ORIGINAL ARTICLE

\title{
Developing a rapid diagnosis and treatment centre: estimating impact on hospital resources
}

\author{
R Hardern, A Taylor, R Shelton, A Russell
}

Emerg Med J 2004;21:165-169. doi: 10.1136/emj.2003.012831

See end of article for authors' affiliations

....................

Correspondence to:

Dr R D Hardern, Accident and Emergency, University Hospital of North Durham North Road, Durham DHI 5TW, UK;

richard.hardern@

ndhent.northy.nhs.uk

Accepted for publication 18 November 2003
Objectives: To determine the possible impact on hospital bed occupancy if a "rapid diagnosis and treatment centre" (RDTC) were operational; to determine the number of patients that such a unit should be able to accommodate to avoid delays in transfer to this unit.

Design: Retrospective review of accident and emergency (A\&E) department notes from consecutive adults over a 16 day period.

Setting: City centre teaching hospital with 1330 beds and 105000 A\&E new attendees per annum. Main outcome measures: Total number of bed days saved per annum (and daily average, assuming no variation by season or day of the week) and the expected occupancy of the RDTC according to the time of day.

Results: The expected daily bed saving was estimated to be 16. Average occupancy was expected to be between six and eight (with little diurnal variation) and a unit with 10 beds would be sufficiently large to avoid delays for $85 \%$ of patients transferred there from A\&E.

Conclusions: On the basis of a "paper exercise" an RDTC would be expected to be beneficial in terms of bed utilisation; careful evaluation of the effects of such a unit in operation should be undertaken.
$\mathrm{O}$ ne of the challenges facing the NHS is the volume of acute work. ${ }^{1}$ It is not unusual for hospitals to run with a bed occupancy rate above $85 \%$ for acute medical wards. It has been shown with a mathematical model that such a high occupancy rate is associated with long waits for admission, usually in the accident and emergency (A\&E) department. ${ }^{2}$ These delays are, at best, uncomfortable and inconvenient for patients and their relatives, are frustrating for A\&E staff, and impair the quality of care that can be provided to other patients in the A\&E department. In some cases these delays seem likely to contribute towards adverse outcomes.

A number of ways of reducing the volume of emergency admissions have been examined. ${ }^{34}$ The concept of a unit that aims to quickly (over hours) and safely resolve the question of whether or not a patient requires admission (or can be managed without admission) is appealing. The impetus for such units (often known as rapid diagnosis and treatment centres) came initially from insurers in the USA who were unwilling to reimburse hospitals for the costs of an admission to rule out a myocardial infarction (or similar condition) if investigations proved to be negative. ${ }^{5}$ As a result, hospitals were forced to look at ways in which serious conditions could be excluded quickly and accurately in those patients with presentations that were consistent with, but not typical of serious conditions. Although the lack of reimbursement for such patients is not so transparent in the NHS, resources clearly are limited; the appeal of such a unit in the UK, if successful, is that it might provide a safe and acceptable way of avoiding admission in a large number of patients.

A paper discussing practices to cope with pressures in acute medicine did not mention the use of a specific unit of this type, although it did mention the value of rapid diagnostic services. ${ }^{6}$ It showed that admissions wards were common (in the hospital of $70 \%$ of the respondents) and were generally viewed as being successful. A way of working that is able to add to the value of admissions wards is likely to increase their success at "coping" with acute medicine.
Although others have described the effects of an "RDTC approach" on specific conditions, we know of no paper that evaluates the effect of a RDTC. Without any evidence base, few commissioners would be willing to make the investment required to establish this type of unit. We aimed to assess the potential impact of such a unit on ward bed occupancy by reviewing the A\&E notes of consecutive patients, determining how many patients would have been eligible for RDTC care had one been operational, and then estimating the probable number of admissions, and their duration, that would have been avoided.

\section{METHODS}

Based on protocols in use in Detroit and Cincinnati (R Nowak and A Storrow, personal communications), draft protocols were developed for the management of 28 conditions where it was felt RDTC care might be beneficial. A key element of each protocol was a rigid time limit. Also included in each protocol were inclusion and exclusion criteria (patients who clearly require admission or who are clearly fit for discharge are not suitable for RDTC management) together with unambiguous criteria about the need for admission both during the protocol and at its completion.

Consecutive A\&E cards from a 16 day period (3 to 18 April 1999, inclusive) were reviewed retrospectively by AT or RS to identify those patients who would have been suitable for RDTC care. The following data were collected:

- Age

- Date and time of presentation to A\&E

- Final disposal-that is, whether admitted, discharged, or observed on A\&E observation ward

- The time of admission was also noted so that occupancy of the "virtual" RDTC could be tracked.

Data from previous inpatients were retrieved to establish the average length of stay for the conditions for which protocols were used. Admissions less than 24 hours in duration were considered to have a length of stay of 0 . 
Difficulty was experienced mapping A\&E presentations (for example, suspected deep vein thrombosis) to discharge codes; codes that were thought to represent patients in whom such diagnoses were ruled out were included. We found the data for length of stay were longer than anticipated but chose to stick with the original study design; the data are shown in table 3 so readers can compare with length of stay in their own institution.

The length of stay for patients discharged from A\&E was not included; this was not a stay that was amenable to reduction. Previous literature ${ }^{5-9}$ was used to provide a guide for the proportion of patients who would be discharged at the end of each protocol and estimates made when such literature was not available.

Using these data it was possible to estimate the impact of an RDTC on the requirement for ward beds (see appendix). The median was used as the "average" in view of the comparatively small numbers involved.

\section{RESULTS}

During the 16 days of the study 4165 patients attended A\&E and the medical receiving room (an area for stable medical patients referred directly from their GP). Altogether 225 were eligible for RDTC management (5.4\%). Eighteen per cent of these patients were admitted to the A\&E observation ward, $32 \%$ were discharged from A\&E and the remainder (50\%) admitted to a ward. Table 1 details the proportion of patients eligible for each protocol. The protocol likely to be of direct benefit to most patients was that for the exclusion of acute myocardial infarction.

Average occupancy (of the "virtual" RDTC) was estimated to be between 6 and 8 at most times of day (fig 1). No evidence of diurnal variation in occupancy was found (of relevance when planning staffing). Extra beds would be required to avoid delays in transfers from A\&E to the RDTC,

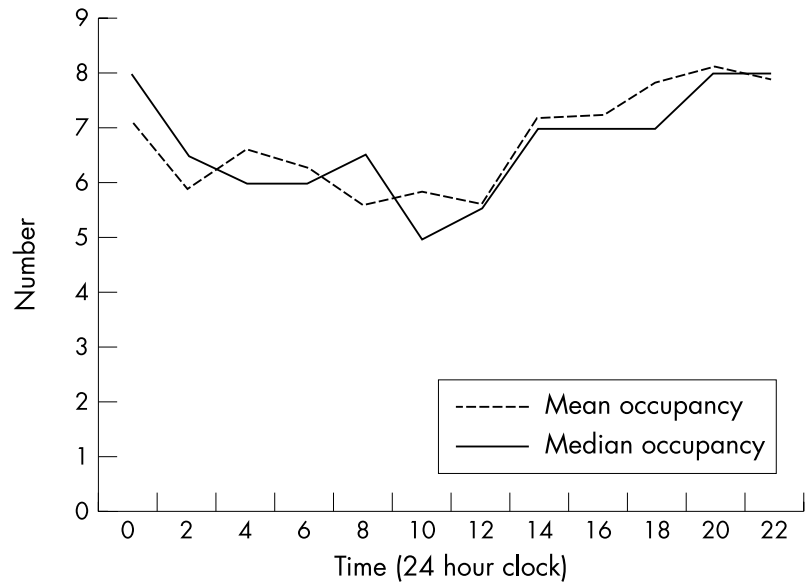

Figure 1 Occupancy by time of day.

10 being the number needed to reduce the proportion of patients experiencing delay to less than $15 \%$ (table 2 ).

The "average" lengths of stay among patients who had previously been admitted with the conditions included in this study are shown in table 3. As the numbers are comparatively small these have been expressed as median. This table also includes assumptions made about the proportion of patients who would be discharged at the end of each protocol and the anticipated duration of each protocol (if some investigations were not available at night, for example, a larger RDTC would be required).

The anticipated effects on bed use, by condition, are also shown in table 3. It was found that for some conditions (such as suspected acute coronary syndrome) the introduction of an RDTC could facilitate safe discharge from hospital earlier

Table 1 Frequency and cumulative frequency of conditions that would be managed on RDTC

\begin{tabular}{lll}
\hline & & Cumulative \\
Condition & Number of patients & percentage \\
\hline Chest pain, suspected myocardial infarction & 46 & 20.4 \\
Deliberate self harm & 25 & 31.6 \\
Suspected pulmonary embolus & 21 & 40.9 \\
Head injury & 16 & 48.0 \\
Pneumonia & 10 & 52.4 \\
Suspected appendicitis & 9 & 56.4 \\
Suspected cholecystitis & 9 & 60.4 \\
Social problems & 8 & 64.0 \\
Suspected deep vein thrombosis & 8 & 67.6 \\
Headache & 8 & 71.1 \\
Exacerbation of COPD & 8 & 74.7 \\
Cellulitis & 7 & 77.8 \\
Pyelonephritis & 6 & 80.4 \\
Abscess & 6 & 83.1 \\
Transient ischaemic attack & 4 & 84.9 \\
Exacerbation of asthma & 4 & 86.7 \\
Vertigo & 4 & 88.4 \\
First fit & 4 & 90.2 \\
Exacerbation of congestive cardiac failure & 4 & 92.0 \\
Pneumothorax & 4 & 93.8 \\
Upper gastrointestinal bleed & 3 & 95.1 \\
Blunt chest trauma & 2 & 96.0 \\
Hypoglycaemia & 2 & 96.9 \\
Renal colic & 2 & 97.8 \\
Smoke inhalation & 2 & 98.7 \\
Dehydration & 1 & 99.1 \\
Allergy & 1 & 99.6 \\
Hyperglycaemia & 1 & 100.0 \\
\hline
\end{tabular}




\begin{tabular}{ll}
$\begin{array}{l}\text { Table } 2 \\
\text { transfers to RDTC }\end{array}$ \\
\hline Beds on RDTC & $\begin{array}{l}\text { \% Eligible patients that could be transferred } \\
\text { without delay }\end{array}$ \\
\hline 16 & 100 \\
15 & 99.0 \\
14 & 97.4 \\
12 & 95.8 \\
11 & 92.2 \\
10 & 87.5 \\
\hline
\end{tabular}

than currently occurs. This would decrease the length of time individual patients remained in hospital (among those in whom continuing admission was unhelpful). For other conditions (such as hyperglycaemia), it appeared that the RDTC would increase bed occupancy (because of a high discharge rate at present directly from $A \& E$ ); adherence to an RDTC protocol for these conditions might be valuable by increasing the "safety" of some of the discharges from A\&E (this factor should be considered when considering the cost effectiveness of this type of unit).

\section{DISCUSSION}

The key finding of this study is that an RDTC would be expected to reduce pressure on the hospital bed base (the most conservative estimate being the release of 16 ward beds per day). An immediate benefit one would expect from reduced pressure on hospital beds would be a reduction in the length of time patients wait in $\mathrm{A} \& \mathrm{E}$ for admission. A previous review of medico-legal claims arising from the care of patients admitted as medical emergencies found that inappropriate discharge was a factor in 9 of 40 cases. ${ }^{10}$ The RDTC would also be expected to increase the safety of discharge from A\&E, and any future cost effectiveness analysis should incorporate this. This study does not address the important issue of cost effectiveness.

It is noteworthy that there was no apparent diurnal variation in occupancy in the "virtual" RDTC; the service should be available at all times. The shortage of senior staff (and the presence of other demands on their time, such as meeting targets to review patients with suspected cancer) makes it unlikely that any hospital will be able to provide a 24 hour a day consultant presence to discharge patients. The RDTC approach may be an acceptable compromise: provided each patient is reviewed at some time by a senior member of staff to ensure they are being managed according to the right protocol, and provided patients are discharged only after meeting specific discharge criteria, predetermined by senior staff in the development of each criterion, discharge is likely to be as safe as possible with existing staff numbers.

A potential strength of the RDTC approach is the fact that patients' discharge can take place as soon as clinical criteria are met. If discharges from hospital are delayed, bed occupancy increases leading to a greater risk of delays getting into a medical ward. Previous papers have commented on the value of frequent senior rounds on medicine in expediting discharge. ${ }^{611}$

Any retrospective analysis has inherent weaknesses. For each potential RDTC protocol small numbers of eligible patients were involved. This may lead to inaccuracies in the estimates of average length of stay or bed saving. All the A\&E (cards/notes) for the relevant period were closely examined

Table 3 Assumptions about current length of stay and discharge rates after RDTC protocol and anticipated reduction in ward bed use after the introduction of an RDTC

\begin{tabular}{|c|c|c|c|c|}
\hline Condition & $\begin{array}{l}\text { Current median LOS } \\
\text { (days) }\end{array}$ & $\begin{array}{l}\text { Estimated proportion discharged } \\
\text { at end of protocol }\end{array}$ & $\begin{array}{l}\text { Length of draft } \\
\text { protocol (h) }\end{array}$ & $\begin{array}{l}\text { Annual reduction } \\
\text { in ward bed use }\end{array}$ \\
\hline $\begin{array}{l}\text { Chest pain, suspected myocardial } \\
\text { infarction }\end{array}$ & 2.5 & 0.8 & 6 & 430 \\
\hline Deliberate self harm & 0 & 0.95 & 6 & -20 \\
\hline Suspected pulmonary embolus & 2.5 & 0.75 & 6 & 121 \\
\hline Head injury & 0 & 0.9 & 8 & -11 \\
\hline Pneumonia & 8 & 0.7 & 12 & 1560 \\
\hline Suspected appendicitis & 2 & 0.8 & 12 & 122 \\
\hline Suspected cholecystitis & 3 & 0.8 & 24 & 311 \\
\hline Social problems & 1 & 0.75 & 4 & -123 \\
\hline Suspected deep venous thrombosis & 8.5 & 0.75 & 6 & 527 \\
\hline Headache & 4 & 0.85 & 16 & 347 \\
\hline Exacerbation of COPD & 7 & 0.75 & 18 & 607 \\
\hline Cellulitis & 2 & 0.5 & 24 & 208 \\
\hline Pyelonephritis & 1 & 0.95 & 18 & 87 \\
\hline Ábscess & 1 & 0.9 & 6 & 84 \\
\hline Transient ischaemic attack & 7 & 0.9 & 24 & 421 \\
\hline Exacerbation of asthma & 2 & 0.8 & 6 & 55 \\
\hline Vertigo & 3 & 0.85 & 12 & 96 \\
\hline First fit & 1 & 0.8 & 12 & -18 \\
\hline $\begin{array}{l}\text { Exacerbation of congestive cardiac } \\
\text { failure }\end{array}$ & 25 & 0.55 & 24 & 834 \\
\hline Pneumothorax & 0 & 0.95 & 6 & -21 \\
\hline Upper gastrointestinal bleed & 1 & 0.95 & 16 & 65 \\
\hline Blunt chest trauma & 2 & 0.85 & 12 & 77 \\
\hline Hypoglycaemia & 1 & 0.95 & 4 & -2 \\
\hline Renal colic & 1 & 0.8 & 12 & $-\overline{9}$ \\
\hline Smoke inhalation & 1 & 0.9 & 12 & -5 \\
\hline Dehydration & 6 & 0.9 & 12 & 123 \\
\hline Allergy & 1 & 0.95 & 8 & -1 \\
\hline Annual total & & & & 5844 \\
\hline Daily average & & & & 16.0 \\
\hline
\end{tabular}


and considerable time was spent trying to establish as accurately as possible average lengths of stay for each condition. Although some patients who really would have been eligible may have been inadvertently excluded and vice versa; it is not likely that these would substantially affect the findings. The large difference in estimated beds saved according to whether mean or median is used is attributable to the differences found in observed length of stay; the median is probably a more representative "average" because the mean can be affected by one or two outliers.

We believe that this study, albeit retrospective, shows that the RDTC concept has sufficient promise to merit further investigation. A number of important questions remain unanswered. This paper does not answer two important practical questions that those considering setting up an RDTC should address:

1. Is a geographically separate RDTC the best way, or should patients be managed in the "RDTC way" regardless of where they are in hospital?

2. Is A\&E the right specialty to manage these patients, and if so what resources should be transferred to them to carry this out?

This study does not address the views of patients; the assumption that all would prefer to be home sooner may not be valid. Future studies are required to assess the satisfaction and views of all concerned: patients, relatives, hospital staff (including support specialties), and general practitioners. Any "savings" in terms of bed occupancy would need to be weighed against the "costs" of rapid access to laboratory and radiological investigation on a 24 hour, 365 days a year basis. In view of the number of patients currently forced to wait on corridors for admission and the association between delayed admission and poorer outcomes this should be undertaken soon. ${ }^{3}$

In the Leeds Teaching Hospitals NHS Trust, based on the results of this work, two areas were set up in early 2001 to work in the way described in this paper. Between 1 April 2001 and 1 March 2002, they had managed 4344 patients (personal communications, Mr R McMaster, Mr G Johnson, and Dr T Hassan).

The NHS Plan contains a target that by 2004 the average time patients spend in A\&E should be no more than four hours. RDTC care may be one way of moving towards this target. $^{12}$

\section{ACKNOWLEDGEMENTS}

R Shelton was supported by a grant from the Critical Care Division of Leeds Teaching Hospitals NHS Trust. RH visited the RDTC at Cincinnati as Maurice Ellis prizewinner and acknowledges this support and the help from A Storrow, director of that unit.

\section{Contributors}

$\mathrm{RH}$ was responsible for the initiation of the study, overall study design, supervision of protocol development, co-wrote the paper, and acts as guarantor of the paper. AT and RS were responsible for the development of protocols, data collection and analysis. AT co-wrote the paper. AR was responsible for development of databases used.

\footnotetext{
Authors' affiliations

R Hardern, R Shelton, Medical Admissions Unit, The General Infirmary, Leeds, UK

A Taylor, Accident and Emergency Department, The General Infirmary A Russell, Division of Critical Care and Clinical Support Services, The General Infirmary

Conflicts of interest: none declared.

Results from this study were presented by AT at the Annual Meeting of the British Association for Accident and Emergency Medicine at Cambridge, April 2000.
}

\section{APPENDIX: MATHEMATICAL MODEL USED}

1. Effect on ward beds.

2. Requirement for beds on RDTC.

3. Overall effect on bed use.

\section{EFFECT ON WARD BEDS}

For an individual condition:

(a) Reduction in ward bed use* $=$ current bed useexpected bed use (within RDTC)

(*"Bed use" throughout this section refers to beds on wards, and excludes use of RDTC beds.)

(b) Current annual bed use $=$ na $\times$ Lc

- $\left[n_{a}\right.$ : number of patients currently admitted annually with condition]

- [ $L_{c}$ : current average length of stay (days) for condition]

(c) Current daily bed use $=($ na $\times$ Lc $) / 365$

(d) Expected bed use = bed use by those currently admitted+bed use by those currently discharged

(e) Bed use after protocol in (those/patients) currently admitted $=\mathrm{n}_{\mathrm{a}}(\mathrm{x})\left([\mathrm{l}-\mathrm{d}] \times \mathrm{L}_{\mathrm{c}}\right)$

- [d: proportion of patients discharged from RDTC at end of protocol]

(f) Bed use after protocol in those currently discharged $($ from $A \& E)=n_{d} \times a\left([1-d] \times L_{c}\right)$

- [nd: number of patients annually attending $A \& E$ with problem and discharged directly]

- [a: proportion of these patients who would be admitted to RDTC under protocol]

(g) Expected bed use (with operational RDTC) $=n_{a}(x)$ $\left([\mathrm{l}-\mathrm{d}] \times \mathrm{L}_{\mathrm{c}}\right)+\mathrm{n}_{\mathrm{d}} \times \mathrm{a}\left([\mathrm{l}-\mathrm{d}] \times \mathrm{L}_{\mathrm{c}}\right)$

(h) Reduction in ward bed use $=\mathrm{n}_{\mathrm{a}} \times \mathrm{L}_{\mathrm{c}}-\mathrm{n}_{\mathrm{a}} \times([\mathrm{l}-\mathrm{d}]$ $\left.\times \mathrm{L}_{\mathrm{c}}\right)-\mathrm{n}_{\mathrm{d}} \times \mathrm{a}\left([\mathrm{l}-\mathrm{d}] \times \mathrm{L}_{\mathrm{c}}\right)$

(i) Reduction in bed use (all conditions) $=\Sigma\left\{\mathrm{n}_{\mathrm{a}} \times \mathrm{L}_{\mathrm{c}}-\mathrm{n}_{\mathrm{a}}(\mathrm{x})\right.$ $\left.\left([\mathrm{l}-\mathrm{d}] \times \mathrm{L}_{\mathrm{c}}\right)-\mathrm{n}_{\mathrm{d}} \times \mathrm{a}\left([\mathrm{l}-\mathrm{d}] \times \mathrm{L}_{\mathrm{c}}\right)\right\}$

(j) $=\Sigma\left\{\mathrm{n}_{\mathrm{a}} \times \mathrm{L}_{\mathrm{c}} \times \mathrm{d}-\mathrm{n}_{\mathrm{d}} \times \mathrm{a}\left([\mathrm{l}-\mathrm{d}] \times \mathrm{L}_{\mathrm{c}}\right)\right\}$

(k) $=\Sigma\left\{\mathrm{n}_{\mathrm{a}} \times \mathrm{L}_{\mathrm{c}} \times \mathrm{d}-\mathrm{n}_{\mathrm{d}} \times \mathrm{a} \times \mathrm{L}_{\mathrm{c}}(\mathrm{l}-\mathrm{d})\right\}$

(l) $=\Sigma \mathrm{L}_{\mathrm{c}}\left\{\mathrm{n}_{\mathrm{a}} \times \mathrm{d}-\mathrm{n}_{\mathrm{d}} \times \mathrm{a} \times(\mathrm{l}-\mathrm{d})\right\}$

(m) Anticipated number of beds saved (with operational RDTC)

$$
=\frac{\sum L_{c}\left\{n_{a} \times d-n_{d} \times a \times(1-d)\right\}}{365}
$$

Assumptions made:

- Average length of stay for patients admitted after protocol will be the same as current average length of stay.

- Some fluctuation in beds freed would be likely, though annual reduction in bed days should be robust.

- No consideration given to the proportion of patients admitted who would be eligible for RDTC. As not all would be, these formulas probably overestimate bed savings on wards.

\section{RDTC REQUIREMENTS}

(a) RDTC bed requirement for one condition = requirement of those currently admitted+requirement of those currently discharged

(b) Requirement of those admitted $=\mathrm{n}_{\mathrm{a}} \times \mathrm{L}_{\mathrm{e}}$ 
- $\left[L_{e}\right.$ : expected length of stay (days) of patients discharged at end of protocol]

(c) Requirement of those currently discharged from A \& $\mathrm{E}=\mathrm{n}_{\mathrm{d}} \times \mathrm{a} \times \mathrm{L}_{\mathrm{e}}$

(d) RDTC bed requirement for one condition = $\mathrm{n}_{\mathrm{a}} \times \mathrm{L}_{\mathrm{e}}+\mathrm{n}_{\mathrm{d}} \times \mathrm{a} \times \mathrm{L}_{\mathrm{e}}$

(e) $=\mathrm{L}_{\mathrm{e}}\left(\mathrm{n}_{\mathrm{a}}+\mathrm{n}_{\mathrm{d}} \times \mathrm{a}\right)$

(f) Total annual RDTC bed requirement $=\Sigma \mathrm{L}_{\mathrm{e}}\left(\mathrm{n}_{\mathrm{a}}+\mathrm{n}_{\mathrm{d}} \times \mathrm{a}\right)$

(g) Average daily bed requirement on RDTC $\dagger$

$$
=\frac{\sum L_{e}\left(n_{a}+n_{d} \times a\right)}{365}
$$

†Underestimate as fails to take into account diurnal and seasonal variations that may occur.

\section{OVERALL IMPACT ON BEDS}

(a) Annual reduction in bed use $=$ ward bed saving - RDTC bed requirement

(b) Annual reduction in bed use $=\Sigma \mathrm{L}_{\mathrm{c}}\left\{\mathrm{n}_{\mathrm{a}} \times \mathrm{d}-\right.$ $\left.\mathrm{n}_{\mathrm{d}} \times \mathrm{a} \times(\mathrm{l}-\mathrm{d})\right\}-\Sigma \mathrm{L}_{\mathrm{e}}\left(\mathrm{n}_{\mathrm{a}}+\mathrm{n}_{\mathrm{d}} \times \mathrm{a}\right)$

(c) Average number of beds "freed" by RDTC

$$
=\frac{\begin{array}{c}
\sum L_{c}\left\{n_{a} \times d-n_{d} \times a \times(1-d)\right\} \\
-\sum L_{e}\left(n_{a}+n_{d} \times a\right)
\end{array}}{365}
$$

If the number of patients currently discharged from A\&E who would be admitted to RDTC is small, this can be simplified, as $\mathrm{n}_{\mathrm{d}} \times \mathrm{a}$ will be small.

(a) Average number of beds "freed" by RDTC

$$
=\frac{\sum n_{a}\left(L_{c} \times d-L_{e}\right)}{365}
$$

Biggest savings in bed use will be for conditions where the following apply

- common problem ( $\mathrm{n}_{\mathrm{a}}$ high).

- current average length of stay $\left(\mathrm{L}_{c}\right)$ is high.

- high proportion can be discharged at the end of the protocol (d).

- length of stay with protocol $\left(L_{e}\right)$ will be low.

Terms including "average" are calculated using both mean and median.

\section{REFERENCES}

1 Scottish Intercollegiate Working Party. Acute medical admissions and the future of general medicine. Edinburgh: The Royal College of Physicians of Edinburgh, 1998

2 Bagust A, Place M, Posnett JW. Dynamics of bed use in accommodating emergency admissions: stochastic simulation model. BMJ 1999;319:155-8.

3 Clinical Standards Advisory Group. Urgent and emergency admissions to hospital. London: HMSO, 1995.

4 New Zealand Health Technology Assessment. Acute medical admissions: a critical appraisal of the literature. Christchurch: The Clearing House for Health Outcomes and Health Technology Assessment, 1998.

5 Graff LG. Observation medicine. Boston: Andover Medical Publishers, 1993.

6 Mather HM. Coping with pressures in acute medicine. J R Coll Physicians Lond 1998;32:211-18.

7 Ward G, Jorden RC, Severance HW. Treatment of pyelonephritis in an observation unit. Ann Emerg Med 1991;20:258-61.

8 Ammons MA, Moore EE, Rosen P. Role of the observation unit in the management of thoracic trauma. J Emerg Med 1986;4:279-82.

9 McDermott MF, Murphy DG, Zalenski RJ, et al. A comparison between emergency diagnostic and treatment unit and inpatient care in the management of acute asthma. Arch Intern Med 1997; 157:2055-62.

10 Neale G. Risk management in the care of medical emergencies after referral to hospital. J R Coll Physicians Lond 1998;32:125-9.

11 Worth R, Youngs G. Consultant physician of the week: a solution to the bed crisis. J R Coll Physicians Lond 1996;30:211-12.

12 Department of Health. The NHS Plan, a plan for investment, a plan for reform. http://www.nhs.uk/nationalplan/ 